[Agr. Biol. Chem., Vol. 31, No. 9, p. 1047 1053, 1967]

\title{
Nutrition of Threonine
}

\section{Part IV. Changes in Activities of Threonine Decomposition Enzymes in Rat Liver by Exeess Feeding of Lysine and Threonine}

\author{
By Michiko Yamashita, Masao Fujimaki and Yosito Sakurai \\ Department of Agricultural Chemistry, The University of Tokyo, Tokyo \\ Received May 10, 1967
}

\begin{abstract}
The threonine content in blood and urine increased and threonine decomposition ability in liver decreased by feeding lower level of lysine, whereas threonine content in blood and urine decreased and the ability of liver increased gradually with increasing lysine content in diet. These phenomena were owing to the increase of threonine dehydratase activity of liver, which was measured from produced $\alpha$-ketobutyric acid amount, by excess administration of lysine. The phenomena that threonine content in urine decreased and threonine decomposition ability of liver increased with increasing threonine content in diet when adequate amount of lysine was fed, were also ascribed to the increase of the dehydratase activity.

One $\mathrm{m}$ mole of threonine was incubated with liver homogenate in presence of PALP*** at $\mathrm{pH} 8.2$ for 20 and $30 \mathrm{~min}$ and $\alpha$-ketobutyric acid produced was introduced to its 2,4 dinitrophenylhydrazone, which was chromatographed on silica-gel thin-layer plate and determined spectrophotometrically at $395 \mathrm{~m} \mu$ under $N, N$-dimethylformamide.

Other enzyme systems relating to threonine catabolism were also investigated, including threonine aldolase, threonine dehydrogenase and ornithine transaminase, showing no significant changes in activities by excess administration of lysine and/or threonine.
\end{abstract}

\section{INTRODUCTION}

Previously, Freedland and Avery ${ }^{11}$ reported that threonine dehydratase activity in rat liver increased when rats were fed on high protein diet. Ashida and Aoyama ${ }^{21}$ reported that this resulted from tryptophan in protein. It has been recent tendency to study amino acid metabolism from the viewpoint of interrelationship among amino acids. The authors ${ }^{3,4 t}$ have reported that threonine decomposition

\footnotetext{
* Presented at the Annual Meeting of the Japanese Society of Food and Nutrition, Nishinomiya, May 13, 1967.

** Present address, Department of Home Economics, Japan Women's University, Tokyo.

*** Pyridoxal phosphate.

1) R. A. Freedland and E. H. Avery, J. Biol. Chem., 239, 3357 (1964).

2) K. Ashida and Y. Aoyama, Amino Acids (Japan), 7, 2 (1967).
}

ability in rat liver increased to some extent by excess administration of lysine and/or threonine. Tamura et al. ${ }^{51}$ reported on the influence of lysine content in diet on threonine concentration in blood, and the authors ${ }^{61}$ reported on the influence of such a diet on the amount of threonine excreted in urine. These reports suggested that lysine would participate in threonine metabolism. The report of Yoshida et al. ${ }^{7 \prime}$ on fatty liver of rat indicates

3) M. Yamashita and Y. Sakurai, J. Jap. Soc. Food Nutr., 19, 215 (1966).

4) M. Yamashita and Y. Sakurai, ibid., 19, 218 (1966).

5) E. Tamura, Y. Obata, T. Niizeki and N. Matsuno, Amino Acids (Japan), 7, 4 (1967).

6) M. Yamashita and Y. Sakurai, This Journal, 30, 937 (1966).

7) A. Yoshida, K. Noda and K. Moritoki, Amino Acids (Japan), 7, 4 (1967). 
seemingly the possibility of metabolic interrelationship between threonine and lysine. In this connection, the authors have studied on the interrelationship through investigating the enzyme systems relating to threonine catabolism in rat liver.

On the other hand, that threonine dehydratase activity does not change by excess feeding of threonine has been under the influent support since the report of Freedland and Avery. ${ }^{1 "}$ However, the authors obtained previously the results suggesting the possibility that the dehydratase would be substrate-inducible. The present report is also concerned with further investigation on this problem.

\section{EXPERIMENTAL}

Experimental animals. Male rats of the Wister strain weighing about $200 \mathrm{~g}$, which had been fed on basal diet for the first one week and then on the appointed test diet for the following one week, were used.

Diets. The composition of the basal diet was shown in Table I. Lysine added diet was prepared

\section{TABle I. Composition of Basal Diet}

$\begin{array}{lc}\quad \text { Component } & \text { Composition, \% } \\ \text { Casein } & 20 \\ \text { Wheat starch } & 42.5 \\ \text { Sucrose } & 30 \\ \text { Johnson salts* } & 5 \\ \text { Soybean oil } & 1 \\ \text { Cellulose powder } & 1 \\ \text { Vitamin mixture** } & 0.5\end{array}$

* M. S. Mameesh and B.C. Johnson, J. Nutrition, 64, 161 (1958)

** Panvitan powder (Takeda Chemical Industries, Ltd.)

by adding $180 \mathrm{mg}$ of lysine hydrochloride to one day amount (about $15 \mathrm{~g}$ ) of the basal diet for an individual animal. Threonine added diet was prepared by adding $100 \mathrm{mg}$ of threonine, and lysine and threonine added diet was prepared by adding $180 \mathrm{mg}$ of lysine hydrochloride and $100 \mathrm{mg}$ of threonine to the basal diet.

Preparation of enzyme solution. The liver was weighed, homogenized for $3 \mathrm{~min}$. under cooling with two volumes of $0.1 \mathrm{M}$ phosphate buffer solution
( $\mathrm{pH} 8.2$ ) and the homogenate was centrifuged at 10,000 r.p.m. for $30 \mathrm{~min}$. at $0 \sim 4^{\circ} \mathrm{C}$. An aliquot of the supernatant was submitted to assay of enzyme activity.

Determination of threonine dehydratase activity. A mixture of $0.5 \mathrm{ml}$ of $12 \mathrm{~mm}$ PALP and $2 \mathrm{ml}$ of the enzyme solution was preincubated for $10 \mathrm{~min}$. at $37^{\circ} \mathrm{C}$, and then $2 \mathrm{ml}$ of $500 \mathrm{mM}$ theonine in $0.1 \mathrm{M}$ phosphate buffer solution ( $\mathrm{pH} \mathrm{8.2)} \mathrm{was} \mathrm{added} \mathrm{to} \mathrm{it.}$ After 10,20, 30 and 45 minutes incubation, $1 \mathrm{ml}$ of $25 \%$ trichloroacetic acid was added to stop the enzyme reaction. The precipitated protein was removed by filtration and residual threonine and produced $a^{*}$ aminobutyric acid in the filtrate were determined with Hitachi Amino Acid Analyzer (KLA-3A). aKetobutyric acid, a main product of the reaction, was determined as follows. A $0.25 \mathrm{ml}$ aliquot of the filtrate was treated with $5 \mathrm{ml}$ of $0.2 \%$ 2,4-dinitrophenylhydrazine in $2 \mathrm{~N}$ hydrogen chloride. After the mixture was left to stand overnight, 2,4-dinitrophenylhydrazones produced were extracted with $6 \mathrm{ml}$ of ethyl formate, and $150 \mu \mathrm{l}$ of the ethyl formate extract was submitted to thin-layer chromatography. The thin-layer plate was prepared from Kieselgel $G$ (Merck) by usual method, and the sample spotted was developed with ethyl formate-petroleum ether $(9: 26 \mathrm{v} / \mathrm{v})$. It resulted in clear separation of the zone corresponding to 2,4-dinitrophenylhydrazone of $\alpha$-ketobutyric acid (Fig. 1), which was extracted with $6 \mathrm{ml}$ of $N, N$-dimethylformamide. After filtration, the optical density of the filtrate was measured at the wave length of $395 \mathrm{~m} \mu$. A complete linear relationship between $\alpha$-ketobutyric acid amount, A $\mu$ moles, in

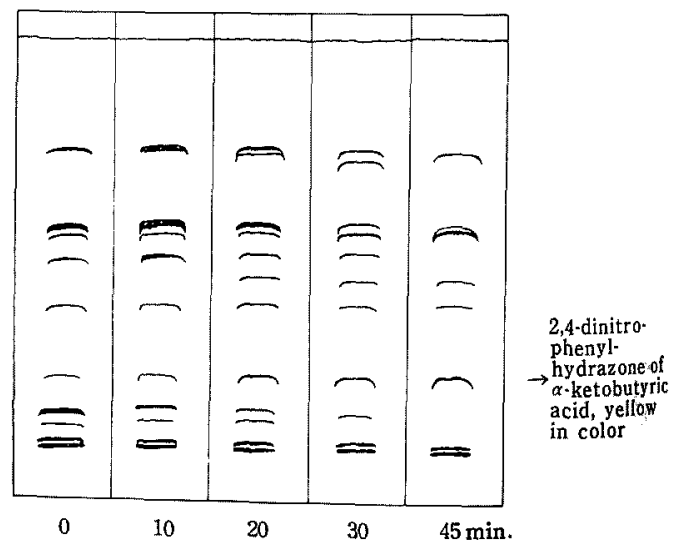

FIG. 1. Examples of Thin-layer Chromatograms of 2,4-Dinitrophenyldrazones at Various Incubation Times. 
$0.25 \mathrm{ml}$ of trichloroacetic acid soluble fraction and optical density, $D$, was obtained below $A=10$. The calibration formula calculated by the most probable method was: $A=9.804 D$.

Fig. 1 also shows the appearance and disappearance of other miscellaneous hydrazones at various incubation times, meaning the necessity of determining the amount of $\alpha$-ketobutyric acid itself, apart from some possible effects of these compounds, in spite of the current method of determination that the amount is calculated from the difference in color intensity between the test sample and the control one.

The threonine dehydratase activity can be represented by the produced $\alpha$-ketobutyric acid amount for the reason as mentioned later.

Determination of threonine aldolase activity. The activity was represented by the amount of acetaldehyde produced. The enzyme reaction was performed, in the similar manner to the above description, in a $50 \mathrm{ml}$ Erlenmeyer flask with an air-tight stopper. After 30 minutes incubation, the flask was dipped in boiling water for $1 \mathrm{~min}$. to stop the reaction. The amount of acetaldehyde produced was determined by gas chromatography. A Shimadzu Model GC-1C gas chromatographic unit, employing a hydrogen flame ionization detector, was used. The column of $3 \mathrm{~mm}$ in inside diameter and $200 \mathrm{~cm}$ long was packed with tricresyl phosphate (10 parts) on Diasolid L (90 parts). The column temperature was $50^{\circ} \mathrm{C}$ and the flow rate of carrier gas was $20 \mathrm{ml}$ per min. A given volume of the head space of the reaction flask was injected with an syringe. The retention time observed was $0.8 \mathrm{~min}$. The amount of acetaldehyde calculated from the peak area was corrected with the recovery percent which had been obtained previously.

Determination of threonine dehydrogenase activity. To the reaction mixture rnentioned above were added furthermore $0.5 \mathrm{ml}$ of $10 \mathrm{~mm}$ NAD and $0.5 \mathrm{ml}$ of $20 \%$ isopropylamine. Incubation was done at $37^{\circ} \mathrm{C}$ for $30 \mathrm{~min}$. The reaction was stopped by an addition of trichloroacetic acid. The presence of aminoacetone formed was detected by paper chromatography according to Elliott. ${ }^{8)}$ Authentic aminoacetone as standard reference was synthesized by the method of Gabriel.9) Determination of it was performed using a modified Ehrlich's reagent of Mauzerall

8) W. H. Elliott, Biochem. J., 74, 90 (1960).

9) S. Gabriel, Ber. dtsch. chem. Ges., 26, 2097 (1893). and Granick.10\} The presence of 1-amino-2-propanol was similarly detected by the paper chromatography and was also determined by gas chromatography, at $200^{\circ} \mathrm{C}$ by the column temperature, the other conditions of operation resembling the case of acetaldehyde. The retention time observed was approximately 18 $\min$.

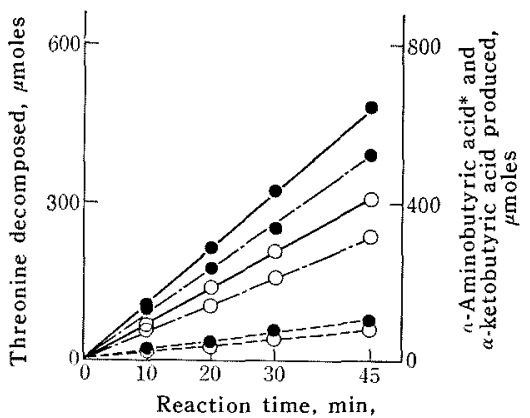

FIG. 2. Increase of Threonine Dehydratase Activity by Administration of Lysine Added Diet.

- Lysine added diet $\bigcirc$ Basal diet

- Threonine decomposed

-- $\alpha$-Ketobutyric acid produced

- - $\alpha$-Aminobutyric acid produced

* Represented in 10 times scale.

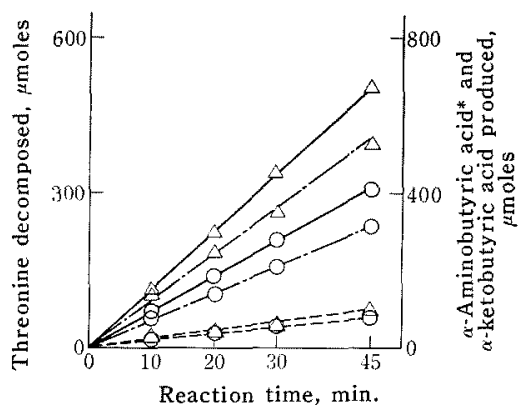

FIG. 3. Increase of Threonine Dehydratase Activity by Administration of Threonine Added Diet.

$\triangle \quad$ Threonine added diet

$\ldots-\alpha$-Ketobutyric acid produced

- - $\alpha$-Aminobutyric acid produced

* Represented in 10 times scale.

10) D. Mauzerall and S. Granick, J. Biol. Chem., 219, 435 (1956). 


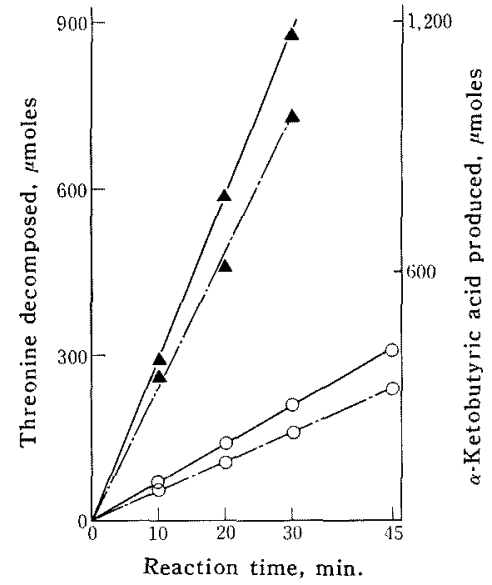

FIG. 4. Increase of Threonine Dehydratase Activity by Administration of Lysine and Threonine Added Diet.

Lysine and threonine added diet
Basal diet
Threonine decomposed
$\alpha-$ Ketobutyric acid produced

\section{RESULTS}

Threonine dehydratase activity. As shown in Fig. 2, the threonine dehydratase activity of liver of rat fed on lysine added diet was distinctly higher than that of liver of rat fed on basal diet. Fig. 3 shows that the effect of excess feeding of threonine also resulted in distinct increase of the $\alpha$-ketobutyric acid amount in comparison with the control. Further increase of the amount was observed, as shown in Fig. 4, in case of simultaneous excess feeding of lysine and threonine. These figures show that the decomposition of threonine and the appearance of the products are the first-order reactions and that the amount of the substrate is sufficient for the enzyme. In the experimental conditions in vitro used here, the main product from the substrate, threonine, in the reaction catalyzed by the dehydratase was $\alpha$-ketobutyric acid, a part of which changed, without suffering from decarboxylation, into $\alpha$-aminobutyric acid through transamination by ornithine transaminase. In
Fig. 5 the amount of $\alpha$-ketobutyric acid was plotted against the total amount of $\alpha$-ketobutyric acid and $\alpha$-aminobutyric acid without consideration of the sorts of diets and the incubation times, indicating the existence of a

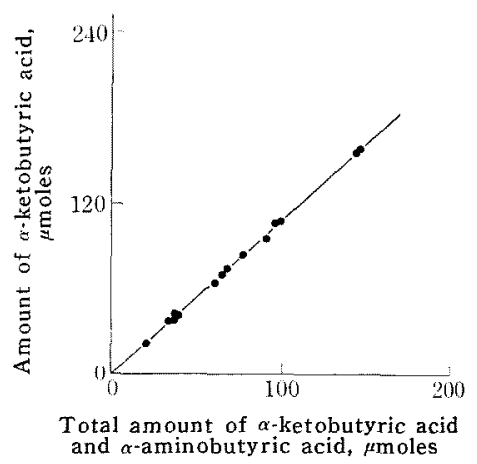

FIG. 5. Correlationship between Total Amount of $\alpha$-Ketobutyric Acid and $\alpha$-Aminobutyric Acid, and Amount of $\alpha$-Ketobutyric Acid.

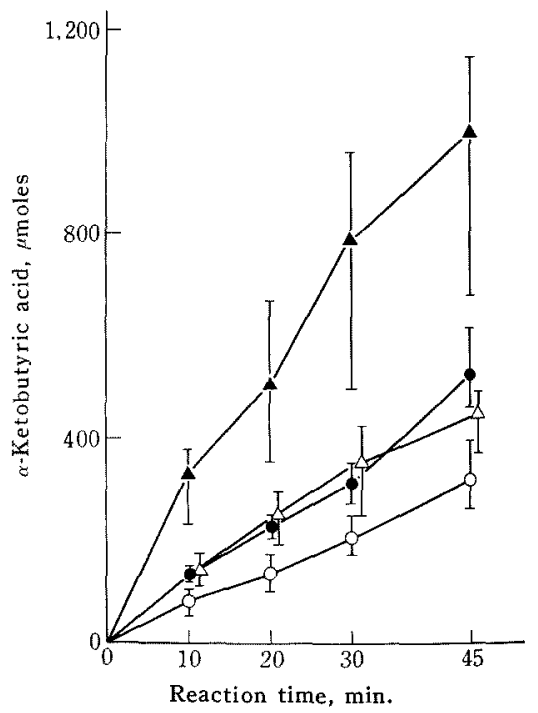

FIG. 6. Effect of Lysine and/or Threonine-Added Diets on Threonine Dehydratase Activity as Measured by $\alpha$-Ketobutyric Acid Amount.

A Lysine and threonine added diet

$\triangle$ Threonine added diet

- Lysine added diet

- Basal diet 
high correlationship between the two. Therefore, the representation of the dehydratase activity by $\alpha$-ketobutyric acid amount only was sufficiently satisfactory, although it must be represented in correctness by the total amount. Figs. 2, 3 and 4 also indicate that there exists a complete linear relationship between the rate of threonine decomposition and that of $\alpha$-ketobutyric acid production, which affirms that the amount of $\alpha$-ketobutyric acid can be an index of the threonine decomposition ability of rat liver. Fig. 6 shows the dehydratase activity as measured from $\alpha$-ketobutyric acid amount. Difference of the mean values at the incubation time $20 \mathrm{~min}$. between the lysine added diet group and the basal diet group was submitted to $t$-test, and significant difference was found at $5, \%$ level, where the sample number for each block was 4 . Such a difference was also found between the threonine added diet group and the basal diet group. At the prolonged stage of the incubation these differences were also observed.

Threonine aldolase activity. In cases of rats fed on basal diet, the amounts of lysine added diet, threonine added diet and lysine + threonine added diet were 3.0, $3.3 \quad 3.8$ and 2.9 $\mu$ moles, respectively. No significant difference was found among those.

Threonine dehydrogenase activity. Both aminoacetone and 1-amino-2-pronanol could be detected chromatographically but these amounts were negligibly small.

\section{DISCUSSION}

It has been the object of recent attention that there exist interrelationships among amino acids in their metabolic processes. Concerning the participation of lysine in threonine metabolism, Tamura et al. ${ }^{11}$ have reported that threonine concentration in blood decreased gradually with increasing lysine content in diet, and the authors ${ }^{4)}$ have reported that

11) E. Tamura, J. Jap. Soc. Food Nutr., 18, 57 threonine amount excreted in urine decreased similarly with increasing lysine content in diet. According to the report of Yoshida et al.," rats suffered from fatty liver by feeding low protein diet containing excess amount of methionine, which was inhibited by the further supply of the diet with threonine, but when rats were fed on the same diet imbalanced with lysine, they suffered from fatty liver, in spite of addition of threonine. In order to account for the causes of these phenomena, the changes in activities of several enzymes in liver relating to threonine catabolism should be investigated.

The main pathway of threonine catabolism in vivo is that by threonine dehydratase which is known to be inducible by feeding of high protein diet and by excess feeding of tryptophan. That the biosynthesis of the dehydratase is sensitively controlled, when the nutritional condition concerning threonine metabolism changes, is reasonable from the viewpoint of homeostasis.

As for the threonine catabolism in vivo, the presence of three pathways has been known (Fig. 7). The first is the pathway by threonine dehydratase, which catalyzes the change of threonine into $\alpha$-ketobutyric acid. ${ }^{12)}$ This keto acid changes into $\alpha$-aminobutyric acid through transamination catalyzed by ornithine transaminase. ${ }^{131}$ The second is that by threonine aldolase, which catalyzes the decomposition of threonine to glycine and acetaldehyde. ${ }^{14}$ The third is that by threonine dehydrogenase, which changes threonine into 2-amino-aceto-acetate, an intermediate product. This decomposes spontaneously to aminoacetone through non-enzymatic decarboxylation. ${ }^{15}$ Aminoacetone is equilibrated

12) X, Matsuo and D. M. Greenberg, J. Biol. Chem., 230, 545 (1958).

13) C. Peraino and H. C. Pitot, Biochim. Biophys. Acta, 73, 222 (1963).

14) S.C. Lin and D.M. Greenberg, J. Gen. Physiol,, 38, 181 (1954).

15) G. Urata and S. Granick, J. Biol. Chem., 238, 811 (1963). 


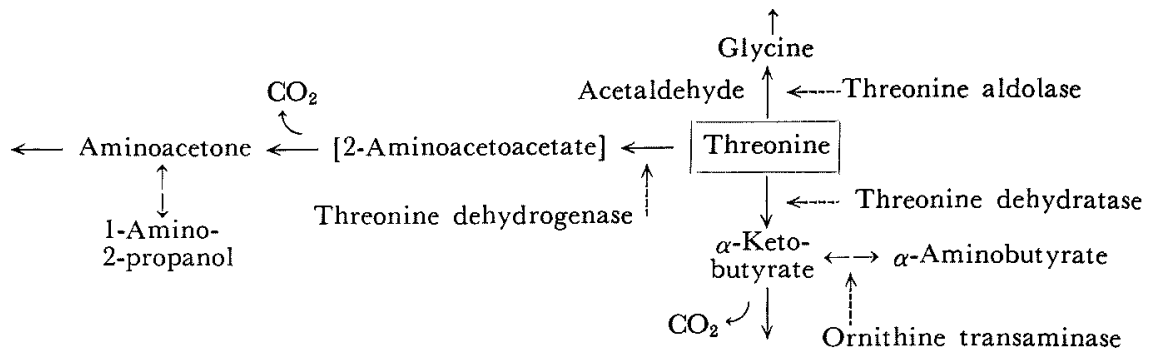

FIG. 7. Metabolic Pathways of Threonine.

with 1-amino-2-propanol via aminopropanol dehydrogenase in liver mitochondria. ${ }^{16}$ !

The optimal $\mathrm{pH}$ of the adolase is 7.6 , and it is known that the activity decreases prominently at $\mathrm{pH}$ 8.2. According to the previous studies by the authors, the decomposition of threonine reached its maximum rate at $\mathrm{pH} 8.2$, which indicated the negative participation of the enzyme in threonine catabolism. In fact, the mole ratio of produced acetaldehyde to decomposed threonine was below 0.02 at this $\mathrm{pH}$. Further related experiments were carried out at $\mathrm{pH} 7.6$, but the activity as measured by produced acetaldehyde amount was too low to be discussed.

Concerning threonine dehydrogenase, the amount of threonine decomposed by the enzyme is known to be small. ${ }^{151}$ The results obtained here also indicates the unimportance of the enzyme in threonine catabolism.

Fig. 5 shows that a complete linear relationship has been obtained between the total amount of produced $\alpha$-ketobutyric acid and $\alpha$-aminobutyric acid, and the amount of $\alpha$ ketobutyric acid regardless of the sorts of the diet; this means that ornithine transaminase is not involved in the increase of the threonine decomposition ability and that the amount of $\alpha$-aminobutyric acid depends only upon the substrate concentration. In the experimental conditions applied here, the decarboxylation

16) I. J. Higgins, M. A. Pickard, J. M. Turner and A.J. Willetts, Biochem. J., 99, 27p (1966). of $\alpha$-ketobutyric acid was negligible at $\mathrm{pH} 8.2$.

The remainder participating in threonine catabolism can be threonine dehydratase. That the optimal $\mathrm{pH}$ of threonine decomposition in vitro is 8.2 , has suggested that the main pathway of the reaction is concerned in threonine dehydratase, and this fact was identified from the present experiment that only the dehydratase activity increased remarkably by lysine administration. The increase of the ability may be due to induction of the enzyme, but the detail investigation on this problem was reserved here.

On substrate induction of threonine dehydratase Greenberg et al. ${ }^{171}$ reported first in 1956. They found that the dehydratase activity increased as much as 3.3 times of the average control value after $5 \mathrm{hr}$. from the intraperitoneal injection of $2 \mathrm{~m}$ moles of $\mathrm{DL}-$ threonine. But Behrman et al. ${ }^{18)}$ made a denial of the substrate induction through their experiments of intraperitoneal injection and oral administration of excess amount of threonine. Freedland and Avery $^{11}$ have obtained the similar negative results as for the induction in cases of rats fed on $6 \%$ excess DLthreonine for 6 days. The similar results have been reported by Protasova. ${ }^{19)}$

According to the authors' results, the de-

17) F. W. Sayre, D. Jensen and D. M. Greenberg, J. Biol. Chem., 219, 111 (1956).

18) L. Goldstein, W. E. Knox and E. J. Behrman, ibid., 237, 2855 (1962).

19) T. N. Protasava, Biokhimiya, 30, 836 (1965). 
hydratase activity of rat fed on threonine excess diet for 1 week increased significantly in comparison with the control group. This suggests the possibility of the substrate induction in spite of these negative reports on this

problem.
No comparative discussion about this dis- Research Foundation. cord is offered because no detail description of the diet composition is shown in these reports.

Acknowledgements. This research has been financed in part by Tanabe Amino Acid Research Foundation. 